\title{
OS DIREITOS SOCIAIS SOB O CRIVO DA AUSTERIDADE: BREVES REFLEXÕES SOBRE AS CONSEQUÊNCIAS DAS MEDIDAS DE CORTES NA EDUCAÇÃO, SAÚDE E PREVIDÊNCIA
}

\author{
José Adércio Leite Sampaio ${ }^{1}$ \\ Larissa de Moura Guerra Almeida ${ }^{2}$
}

\section{RESUMO}

Face à crise econômica, a austeridade tem papel importante na redução das despesas públicas, dado o déficit orçamentário dos países em turbulência. Apesar de vistas como alternativa à crise, as medidas austeras apresentam consequências danosas a direitos sociais, como educação, saúde e previdência. Mediante pesquisa bibliográfica em textos recentes e a partir de estudo realizado para a Comissão de Liberdades Civis, Justiça e Assuntos Internos do Parlamento Europeu, o presente trabalho visa refletir sobre as implicações da austeridade nos direitos sociais, e a tendência das políticas de cortes no Brasil, que podem ameaçar garantias relevantes ao Estado Democrático de Direito.

Palavras-chave: Austeridade. Direitos sociais. Crise econômica. Controle de gastos. Políticas de cortes.

\section{SOCIAL RIGHTS UNDER THE AUSTERITY CRITERION: BRIEF REFLECTIONS ON THE CONSEQUENCES OF CUTS MEASURES IN EDUCACTION, HEALTHCARE AND PENSIONS}

\begin{abstract}
In the face of the economic crisis, austerity plays an important role in reducing public spending, given the budget deficit of turbulent countries. Although seen as an alternative to the crisis, austerity measures have detrimental consequences for social rights, such as education, healthcare and pensions. Through bibliographic research in recent texts and from a study conducted for the European Parliament's Committee on Civil Liberties, Justice and Home Affairs, this paper aims to reflect on the implications of austerity on social rights, and the tendency of cuts policies in Brazil, which may threaten relevant guarantees to the Democratic Rule of Law.
\end{abstract}

Keywords: Austerity. Social rights. Economic crisis. Spending control. Cuts policies.

\section{INTRODUÇÃO}

\footnotetext{
${ }^{1}$ Procurador da República (MPF-MG). Graduado em Direito pela UFMG. Mestre e Doutor em Direito pela UFMG. Professor Adjunto III da PUC Minas, Professor Titular da Escola Superior Dom Helder Câmara. E-mail: joseadercio.contato@gmail.com. Currículo Lattes: http://lattes.cnpq.br/6500803835232465.

${ }_{2}^{2}$ Advogada e Professora. Graduada em Direito pela PUC Minas. Especialista em Direito Público pelo Instituto de Educação Continuada, PUC Minas. Mestranda em Direito Público, PUC Minas. Professor Orientador: José Adércio Leite Sampaio. E-mail: lah.moura.guerra@gmail.com. Currículo Lattes: http://lattes.cnpq.br/0406208623321421.
} 
Não há como negar que o processo de globalização econômica, ao promover a aproximação entre as diversas sociedades e países existentes no mundo, sobretudo com a integração do mercado, fomentou as relações comerciais com os chamados blocos econômicos, proporcionou o surgimento das empresas multinacionais e a internacionalização dos fluxos de capitais (BAUMAN, 1999, p. 5-7).

Porém, potencializou (e muito) as consequências de crises econômicas, que passaram a atingir níveis também globais. Basta lembrar os efeitos da disseminação global da crise financeira do subprime ${ }^{3}$, iniciada nos Estados Unidos nos idos de 2007 e 2008, nos setores imobiliário e bancário, propagando-se para a Europa e, em seguida, para o resto do mundo (REIS, 2018).

Sabe-se que o impacto exercido pela globalização no mercado de trabalho, no comércio internacional, na liberdade de movimentação e na qualidade de vida da população tem sua intensidade variada, conforme o nível de desenvolvimento dos países - o que acaba por alcançar a promoção e o acesso a importantes direitos, como educação, saúde e previdência.

Neste cenário, se a crise econômica tem a sua capacidade de propagação ampliada, como efeito sinergético, países em situações de caos financeiro, com altíssimos déficits orçamentários, tendem a se valer das mesmas soluções. É o que comumente se observa da utilização de políticas de austeridade para a contenção de gastos públicos.

Ocorre que tal rigor econômico-financeiro das despesas estatais tem sido empregado como a justificativa mais legítima para cortes orçamentários, acarretando graves prejuízos a direitos sociais, sob a necessidade emergente de resolver o déficit público que se tornara insustentável. Direitos como educação, saúde e previdência podem vir a sofrer consequências danosas - principal conclusão de estudo, em 2015, realizado para a Comissão de Liberdades

\footnotetext{
${ }^{3}$ Também conhecida como a "bolha imobiliária americana", a crise do subprime se deu a partir da queda do índice Dow Jones, em vista da concessão de empréstimos hipotecários de alto risco (subprime mortgage), o que levou muitos bancos à situação de insolvência, repercutindo sobre as bolsas de valores de todo o mundo, diante da concessão desenfreada de créditos imobiliários, bem como por falhas na regulação do sistema financeiro que permitia a transferência dos créditos hipotecários em série, permitindo a transferência de riscos para outras partes (REIS, 2018).
} 
Civis, Justiça e Assuntos Internos, do Parlamento Europeu: "O impacto da crise nos direitos fundamentais em Estados-Membros da UE - análise comparativa"4.

Desse modo, tendo em vista este cenário, propõe-se breves reflexões sobre o impacto das medidas de austeridade quanto aos direitos sociais, notadamente na educação, saúde e previdência, adotadas ao longo da crise econômica, a partir de dados já apurados em sete países da Europa, e a tendência das políticas de cortes e contenção de gastos no Brasil.

Por meio de estudo e pesquisa bibliográfica em textos pertinentes e recentes sobre o tema, bem como mediante o exame do estudo realizado para a Comissão de Liberdades Civis, Justiça e Assuntos Internos, do Parlamento Europeu, buscar-se-á analisar possíveis ameaças a direitos e garantias relevantes aos cidadãos, no âmbito do Estado Democrático de Direito.

\section{DO ESTUDO SOBRE OS IMPACTOS DA CRISE ECONÔMICA NOS PAÍSES DA UNIÃO EUROPEIA: A AUSTERIDADE, A CONTENÇÃO DAS DESPESAS PÚBLICAS E O CORTE NOS DIREITOS}

\subsection{Do contexto da crise econômica e saída pela austeridade}

Como dito, a globalização apresenta como um de seus efeitos a integração das relações socioespaciais, configurando-se em redes, além da expansão das empresas transnacionais, a formação dos acordos regionais ou dos blocos econômicos - como é o caso da União Europeia (UE) -, a internacionalização dos fluxos de capitais e, sem dúvida, o fortalecimento do sistema capitalista (BAUMAN, 1999, p. 5-7).

$\mathrm{Na}$ vertente econômica, que para Reinaldo Gonçalves "pode ser entendida como a ocorrência simultânea de três processos" (GONÇALVES, 2002, p. 3) - crescimento extraordinário dos fluxos internacionais de bens, serviços e capital; acirramento da concorrência internacional; e crescente interdependência entre agentes econômicos e sistemas econômicos nacionais - devido à aproximação dos países por meio do mercado, tem-se em consequência o agravamento das crises financeiras por eles sofridas, em decorrência dessa "maior instabilidade sistêmica da economia internacional” (GONÇALVES, 2002, p. 10).

E, com a União Europeia, não foi diferente.

\footnotetext{
4 "The impact of the crisis on fundamental rights across Member States of the EU - Comparative analysis" (tradução livre).
}

Revista de Direitos Sociais, Seguridade e Previdência Social | e-ISSN: 2525-9865 | Belém |

v. 5 | n. 2 | p. 23 - 44 | Jul/Dez. 2019. 
A fim de conter a crise econômica, que começou na Grécia em 2009, ameaçando países como Itália, Espanha e Portugal, bem como as implicações à moeda única e as dúvidas quanto à solvência do sistema bancário europeu (BLYTH, 2017), o debate em torno das medidas de austeridade implementadas pelos membros da União Europeia - e copiadas por outros países no mundo que também se encontram em situações de turbulência financeira -, tem recebido destaque nos últimos anos.

Sobretudo, pelo fato de as políticas de austeridade passarem a ser vistas como o antídoto pragmaticamente necessário e de efeitos imediatos para a redução de gastos públicos e promoção do crescimento econômico.

Mas, afinal, em que consiste a austeridade?

Segundo Mark Blyth (2017), em “Austeridade: a história de uma ideia perigosa”,

Austeridade é uma forma de deflação voluntária em que a economia se ajusta através da redução de salários, preços e despesa pública para restabelecer a competitividade, que (supostamente), se consegue melhor cortando o orçamento do Estado, as dívidas e os déficits. (BLYTH, 2017, posição 194)

Dessa forma, o governo de um país que vier a adotar medidas de austeridade deve visar o rigor nas contas públicas, isto é, sobre o excesso de despesas em relação à receita anual dos cofres públicos, buscando corte de despesas, o que por vezes é acompanhado de maior tributação, em especial aumento de impostos, e cortes orçamentários.

Complementa Mark Blyth (2017) sobre a adoção da austeridade:

(...) Fazê-lo, acham os seus defensores, inspirará a "confiança empresarial" uma vez que o governo não estará "esvaziando" o mercado de investimento ao sugar todo o capital disponível através da emissão de dívida, nem aumentando a já "demasiada grande” dívida da nação. (BLYTH, 2017, posição 194)

É cediço que, após a crise financeira internacional de 2008, os níveis de endividamento dos governos aumentaram consideravelmente.

Além dos efeitos da turbulência financeira sobre o setor privado (principalmente nas instituições bancárias) e a consequente recessão, houve queda na arrecadação de impostos algo já esperado pelo aumento do desemprego e redução da capacidade econômica dos contribuintes (SENADO FEDERAL, 2013).

Os governos, ainda, chegaram a ser acusados de terem se excedido em gastos nos períodos de estabilidade econômica, o que levou a inúmeras despesas em empréstimos na 
tentativa de resgatar os bancos do colapso (SARMENTO, 2018). Resultado: o que estava ruim, tornou-se pior com os índices estratosféricos de dívidas públicas.

Logo, neste cenário, o consenso entre líderes e instituições internacionais sobre a introdução de medidas de austeridade parecia inevitável, e, assim, como o melhor caminho para lidar com a crise que se espalhou dos Estados Unidos para a Europa, comprometendo a Zona do Euro e afetando economias inteiras.

Assim, bancos privados e instituições internacionais, como o Fundo Monetário Internacional (FMI), desempenharam papel-chave nessa fase, exigindo a adoção de políticas econômicas austeras pelos países que pretendiam refinanciar suas dívidas, comprometendo-se os governos a reduzir a despesa pública, por meio de cortes drásticos (ou extinção) de subsídios e gastos com a máquina administrativa.

No entanto, apesar do aparente discurso bem-intencionado, a austeridade é composta de políticas, em sua maioria, que preferencialmente propõem cortes de gastos em projetos de desenvolvimento e despesas decorrentes da promoção e acesso a direitos sociais.

Com efeito, as medidas de austeridade se tornaram altamente impopulares, vez que de forma geral têm como resultado cortes em serviços públicos (educação e saúde) e impactos na previdência (aumento da idade para aposentadorias e reduções dos benefícios e proventos), bem como cortes na remuneração de servidores públicos.

\subsection{Do estudo sobre os impactos da crise e os efeitos das medidas de austeridade nos direitos sociais: cortes drásticos na educação, saúde e previdência}

Evidente que a situação de colapso não passou despercebida.

Ao contrário, tendo a austeridade como a resposta principal ao caos econômico instaurado, o corte nos gastos e orçamentos e seus impactos nos direitos dos cidadãos passaram a ser alvo de preocupação, já que houve queda do padrão de vida da população no curto prazo, quando medidas austeras foram adotadas a fim de recuperar o equilíbrio físcal.

Sendo assim, buscando averiguar não apenas os efeitos imediatos observados com a adoção das políticas de austeridade, mas também os impactos vistos depois de anos de corte de gastos públicos, diante da série de reclamações coletivas de ofensa a direitos apresentadas em resposta à crise, o Parlamento Europeu, mediante a Comissão de Liberdades Civis, Justiça e Assuntos Internos promoveu um estudo sobre os impactos da crise econômica nos direitos 
fundamentais dos cidadãos em países membros da União Europeia (UE): “O impacto da crise nos direitos fundamentais em Estados-Membros da UE - análise comparativa".

Conforme consta no estudo (EUROPEAN PARLIAMENT, 2015, p. 12), foram selecionados sete países membros - Bélgica, Chipre, Grécia, Irlanda, Itália, Espanha e Portugal -, em cenários diferentes, a fim de representar a situação geral na UE, uma vez que nem todos os países foram afetados pela crise com a mesma intensidade.

Para os fins que se pretende com a presente análise, far-se-á um recorte nos dados levantados pelo relatório da Comissão de Liberdades Civis, Justiça e Assuntos Internos do Parlamento Europeu quanto aos impactos das medidas de austeridade nos direitos sociais, especificamente na educação, saúde e previdência, direitos que são os primeiros a serem atingidos pelas políticas de cortes e contenção de gastos públicos.

A conceituação dos direitos sociais não é tarefa simples, visto que depende de análise histórica do seu surgimento e necessidade, não podendo ser reduzidos ao rótulo de "direitos prestacionais". Todavia, para análise neste trabalho, os direitos econômicos, sociais e culturais, genericamente denominados como direitos sociais (SAMPAIO, 2013, p. 570-571), são os direitos fundamentais que buscam melhorar as condições de vida e de trabalho para todos os indivíduos, garantidos pelo Estado e que dependem de sua atuação e regulamentação.

Aqui, os direitos sociais abrangem uma gama de direitos, tais como, direitos trabalhistas, seguridade social (direitos à saúde, à previdência social e à assistência social), proteção à maternidade, à infância e aos desamparados.

Consoante Gilmar Ferreira Mendes e outros (2007), no que tange à Constituição da República Federativa do Brasil de 1988 (BRASIL, 1988), nos artigos $6^{\circ}$ ao 11, os direitos sociais são concebidos "como direitos a que correspondem obrigações de fazer, a cargo não apenas do Estado, mas da sociedade, em geral" e afirmados como "direitos de todos e dever do Estado" (MENDES et. al., 2007, p. 674-675).

Veja-se que a problemática que se levanta é justamente a forma de se efetivar tais direitos, já que a sua materialização implica na atuação estatal que, constantemente, defendese com a escassez de recursos públicos sob o escudo da "reserva do possível". Logo, se no contexto de estabilidade financeira, a insuficiência de recursos públicos é uma opção de justificativa à não viabilização de muitos direitos sociais; em um cenário de caos econômico, o que era uma opção, passa a ser uma razão legitimamente arguível. 
Nesse sentido, o referido estudo de 2015, para a Comissão de Liberdades Civis, Justiça e Assuntos Internos, do Parlamento Europeu, aponta clara deterioração de diversos direitos fundamentais, estando entre os mais afetados o direito à educação, à saúde e à previdência, ou seja, direitos sociais.

\subsubsection{Do direito à educação}

Relativamente ao direito à educação, com exceção da Bélgica, seis países (Chipre, Grécia, Irlanda, Itália, Espanha e Portugal) promoveram cortes severos no orçamento.

As principais medidas incluíram: redução no número de escolas, alcançada por fusões ou fechamentos; redução no número de professores; aumento na proporção aluno/professor; redução de custos administrativos e outros custos relacionados à escola. Algumas medidas resultaram na redução dos serviços prestados a crianças em situações de vulnerabilidade, como crianças com deficiência, crianças ciganas e filhos de migrantes. (EUROPEAN PARLIAMENT, 2015, p. 12-13)

Quanto à medida de redução do número de escolas, o estudo identificou que, no Chipre, em média, duas escolas por ano foram fundidas com outras, sendo reduzidas 347 (trezentos e quarenta e sete) escolas, em 2008, para 338 (trezentos e trinta e oito), em $2013^{6}$. $\mathrm{Na}$ Itália, a fusão de escolas afetou principalmente as regiões da Sicília e da Sardenha, onde dois terços das escolas foram fundidas ${ }^{7}$, enquanto que, na Grécia, o número de unidades escolares nas escolas primárias, no período de 1998 a 2012, caiu de 6.431 (seis mil quatrocentos e trinta e um) para 4.716 (quatro mil setecentos e dezesseis) escolas ${ }^{8}$.

Os cortes no funcionalismo também foram drásticos. Exceto a Bélgica, os demais seis países realizaram reduções de salários e do número de funcionários, seja por demissões ou congelamento de novos empregos.

Cidadãos em situação de vulnerabilidade tiveram seu quadro mais agravado. Grécia, Chipre e Irlanda reduziram (quando não extinguiram) muitos programas de apoio às famílias carentes, como ajudas de custo do governo para refeições ou fundos para a compra de

\footnotetext{
5 "The main measures included: a reduction in the number of schools, which was achieved by mergers or closures; a reduction in the number of teachers; an increase in the student-to-teacher ratio; the reduction of administrative and other school related costs. Some measures resulted in reducing the services provided to children in vulnerable situations, such as children with disabilities, Roma children and children of migrants" (tradução livre).

${ }^{6}$ EUROPEAN PARLIAMENT, 2015, p. 44.

${ }^{7}$ Ob. cit., p. 44.

${ }^{8}$ Ob. cit., p. 44.
} 
mobiliário para salas de aula ${ }^{9}$. Em Portugal, o orçamento destinado à educação de crianças portadoras de deficiência foi severamente reduzido, e na Grécia, os cursos de idiomas para filhos de imigrantes foram lamentavelmente diminuídos ${ }^{10}$.

Não há dúvidas de que, mesmo não se podendo averiguar integralmente os efeitos de tais medidas, há sério risco à qualidade de ensino e desenvolvimento de crianças em idade escolar, além do aumento do número de desempregados no setor e comprometimento de outros serviços públicos atrelados à educação: transporte escolar e manutenção das escolas públicas em condições adequadas.

\subsubsection{Do direito à saúde}

No que tange ao direito à saúde, o relatório promovido pelo Parlamento Europeu (2015) apontou que os sete países introduziram medidas que afetaram o acesso aos cuidados com a saúde. Embora a Bélgica tenha optado por adotar medidas que apenas amenizassem as dificuldades, sem remover os serviços, países como Chipre, Grécia e Portugal promoveram mudanças significativas.

Medidas como a restrição do acesso aos cuidados de saúde; introdução ou aumento de taxas de participação; reorganização de hospitais e profissionais de saúde; redução de salários e congelamento do emprego de funcionários; intervenções nos custos de medicamentos e outros serviços; além de reformas administrativas, foram as mais adotadas ${ }^{11}$.

Os impactos das medidas foram observados em: acesso reduzido aos cuidados de
saúde; encargos financeiros adicionais para os cidadãos; redução no número de
equipes e instalações médicas; aumento do tempo de espera para consultas e
cirurgias; alternativas aos cuidados de saúde pública, como serviços privados ou
serviços administrados por ONGs; aumento das necessidades médicas não
atendidas; diminuição dos cuidados preventivos e protetores; mudanças no mercado
farmacêutico - incluindo escassez de suprimentos e queda de preços. Pessoas pobres
e sem-teto, idosos, pessoas com deficiência e suas famílias, mulheres e migrantes
sem documentos estão entre os grupos que foram afetados desproporcionalmente
pelas medidas impostas. (EUROPEAN PARLIAMENT, 2015, p. 12-13) ${ }^{12}$

\footnotetext{
${ }^{9}$ Ob. cit., p. $45-46$.

${ }^{10}$ Ob. cit., p. $46-48$.

${ }^{11}$ EUROPEAN PARLIAMENT, 2015, p. 13.

12 "The impacts of measures were seen in: reduced access to healthcare; additional financial burden for citizens; reduction in the number of medical staff and facilities; increases waiting times for appointments and surgeries; alternatives to public health care, e.g. private services or NGO-run services; increased unmet medical needs; decreased preventive and protective care; changes in the pharmaceuticals market - including shortages in supplies and decreased prices. Poor and homeless people, older people, people with disabilities and their families, women, and undocumented migrants, are among the groups which were disproportionately affected by the measures imposed" (tradução livre).
} 
Com isso, a população assistiu a cortes drásticos nos orçamentos dos hospitais públicos, além do elevado tempo de espera para atendimento, em decorrência da redução de profissionais e número de leitos, até mesmo diminuição de suprimentos médicos (medicamentos, ferramentas e insumos) ${ }^{13}$, comprometendo o acesso aos cuidados de saúde fornecidos pelo Estado. Houve redução de auxílios financeiros dos governos, e, logo, aumento do custo de vida para as famílias: na Grécia, "o acordo de resgate transferiu o ônus da assistência médica do Estado para o paciente, com aumento nas taxas de uso e coparticipação de certos medicamentos, e introdução de taxas de prescrição"14 (EUROPEAN PARLIAMENT, 2015, p. 55).

No Chipre, Grécia, Irlanda, Itália e Espanha, foram registrados tempos de espera alarmantes para serviços, como exames médicos ou cirurgia: no Chipre, o tempo de espera era de sete meses para atendimento, mesmo em situações graves e com risco de morte; na Espanha, em 2012, mais de 570 mil pessoas aguardavam cirurgia; na Irlanda, mais de 480 mil pessoas aguardavam para consultas médicas, sendo que " $17 \%$ já estavam em espera entre um a dois anos, 6,4\% entre dois a três anos, e 5,2\% há mais de três anos para uma primeira consulta” (EUROPEAN PARLIAMENT, 2015, p. 58) ${ }^{15}$.

Ainda mais grave restou o não atendimento das necessidades médicas da população. Muitas pessoas com baixas condições financeiras, devido ao alto custo com os encargos adicionais e as longas listas de espera, deixaram de buscar atendimento médico.

De acordo com o estudo de 2015, para a Comissão de Liberdades Civis, Justiça e Assuntos Internos, do Parlamento Europeu, "14\% da população na Bélgica" (EUROPEAN PARLIAMENT, 2015, p. 59) declarou ter decidido não receber tratamento médico, adiar ou suspender o tratamento por razões financeiras, enquanto que outros tiveram que reduzir seus gastos com habitação, alimentação e educação, a fim de pagar suas despesas médicas ${ }^{16}$. Na

\footnotetext{
${ }^{13}$ EUROPEAN PARLIAMENT, 2015, p. 55-58.

14 "It has, thus, been observed that in Greece, the bail-out agreement shifted the burden of healthcare from the State to the patient, with an increase in user fees and co-payments for certain medicines and the introduction of prescription fees". (tradução livre)

15 " $17 \%$ of these waiting between $12-24$ months, $6.4 \%$ waiting between $24-36$ months, and $5.2 \%$ waiting for over three years for a first appointment" (tradução livre).

${ }^{16}$ EUROPEAN PARLIAMENT, 2015, p. 59.
} 
Grécia, muitos pacientes possuíam a dura realidade de terem que optar por comer ou comprar seus medicamentos ${ }^{17}$.

Ademais, observou-se que a população de baixa renda e grupos mais vulneráveis foram, de fato, os mais desproporcionalmente prejudicados com as medidas de cortes na saúde. Na Irlanda, pessoas portadoras de deficiência mental chegaram a permanecer presas em suas próprias casas, por não haver atendimento médico adequado: em 2010, os gastos com saúde mental caíram de " $13 \%$ para $5,3 \%$ do total de gastos com saúde"18. Na Espanha, imigrantes em situação irregular só poderiam ser atendidos pelo sistema de saúde público em casos de emergência, e, em Portugal, cidadãos que vivem nas áreas rurais teriam cada vez menos acesso aos serviços de saúde, devido ao fechamento de inúmeros hospitais ${ }^{19}$.

Note-se que os cortes orçamentários realizados por esses sete países europeus ameaçaram, e ainda ameaçam, o acesso universal ao direito à saúde, vez que, de modo geral, a assistência médica se tornou um ônus para o cidadão, restringindo-a a condições financeiras e afastando, com isso, justamente aqueles que necessitam do serviço público de saúde.

\subsubsection{Do direito à previdência}

Quanto ao direito à previdência, partindo do pressuposto de que se trata de um direito adquirido e protegido pelas regras gerais aplicáveis à proteção dos direitos de propriedade, o estudo de 2015 da Comissão de Liberdades Civis, Justiça e Assuntos Internos do Parlamento Europeu identificou que os sete Estados-Membros observados fizeram intervenções nos sistemas de previdência, sendo esmagadoras em alguns dos países, mormente relacionadas ao critério de idade da aposentadoria e ao requisito de antiguidade; o cálculo e a reavaliação de pensões; cortes nos montantes das pensões já concedidas; e regras aplicáveis ao trabalho após a aposentadoria.

Ainda que pensionistas possam ser considerados como um grupo vulnerável, os cortes realizados e as mudanças introduzidas pelos governos mais afetaram pessoas, que dentro deste grupo, apresentam condições de maior vulnerabilidade (idosos, trabalhadores de baixa renda, mulheres e portadores de deficiência física e mental), além de incutirem nos trabalhadores a

\footnotetext{
${ }^{17}$ Ob. cit., p. 59.

18 Ob. cit., p. 60.

${ }^{19}$ Ob. cit., p. 61.
} 
permanência em atividade por mais tempo e causarem o retorno de inativos à força de trabalho.

Os impactos das medidas de austeridade no direito à previdência podem ser vistos na diminuição das despesas estatais com pensões e na diminuição do padrão de vida atualmente de muitos pensionistas e de futuros pensionistas ${ }^{20}$. (EUROPEAN PARLIAMENT, 2015, p. 14)

Com as reformas administrativas nos sistemas de previdência, os procedimentos de solicitação e concessão de aposentadorias e benefícios passaram a ser mais demorados, ao ponto de pessoas ficarem sem renda por até dois anos ${ }^{21}$.

Em todos os sete países analisados foram introduzidas reformas críticas no sentido de revisão do critério da idade. Enquanto na Bélgica, Grécia, Espanha, Itália, Irlanda e Portugal, as medidas elevaram imediatamente a idade para aposentadoria para algumas categorias de trabalhadores; no Chipre, foi introduzido um ajuste automático da idade legal para aposentadoria, a cada cinco anos, com base nas mudanças da expectativa de vida ${ }^{22}$.

Desse modo: a Espanha promoverá aumento do critério da idade para aposentadoria até 2027; na Bélgica, de 2012 e 2017, para fins de aposentadoria antecipada de mulheres foi de 35 (trinta e cinco) para 40 (quarenta) anos; na Irlanda, o critério passará de 66 (sessenta e seis) para 68 (sessenta e oito) anos, em 2028, fixando-se a idade máxima em 70 (setenta) anos; e na Itália, o aumento na idade da aposentadoria foi de 66 (sessenta e seis) para 67 (sessenta e sete) anos, em 2012 23 . Além disso, na Bélgica e na Grécia, a idade da aposentadoria para as mulheres aumentou de 60 (sessenta) para 65 (sessenta e cinco) anos, igualando à idade dos homens.

De acordo com o relatório (2015), na Irlanda, foi adotada a obrigação de os empregadores privados introduzirem um plano de pensão para os empregados, e, na Grécia, diversas e frequentes mudanças afetaram a segurança jurídica dos cidadãos, como o corte nas pensões de pais de crianças com deficiência, que haviam optado pela inatividade para maior auxílio nas despesas médicas ${ }^{24}$.

\footnotetext{
20 "The impacts of austerity measures on the right to a pension may be seen in decreased State expenditure on pensions and decreased standard of life for many pensioners currently, and for future pensioners". (tradução livre)

${ }_{22}^{21}$ EUROPEAN PARLIAMENT, 2015, p. 14.

${ }^{22}$ EUROPEAN PARLIAMENT, 2015, p. 84.

${ }^{23}$ Ob. cit., p. 84.

${ }^{24}$ Ob. cit., p. 87.
} 
Dentre as medidas de reforma no sistema previdenciário que alcançarão os futuros pensionistas e beneficiários, as medidas de cortes nas pensões e benefícios já concedidos é que resultaram em impactos mais severos. $\mathrm{Na}$ Grécia, foram introduzidas reduções adicionais "entre $20 \%$ e $40 \%$ ", para pensões principais que excedam um determinado montante, e redução "entre $10 \%$ e $20 \%$ " para as pensões complementares ${ }^{25}$. Na Irlanda, as aposentadorias do setor público foram reduzidas "em média em 4\%", chegando em alguns casos a "cortes de $12 \%$ ", enquanto as aposentadorias do setor privado estão protegidas contra cortes pela Lei de Pensões de $1990^{26}$.

Também as bonificações especiais foram alcançadas: na Grécia, os bônus de Páscoa, de verão e gratificação natalina foram substituídos por um bônus fixo, que foi totalmente abolido em 2013; em Portugal, foram pagos abonos de férias e Natal extras em 2012, sendo “90\% do pagamento de férias abolido em 2013", além de todas as pensões mínimas de seguridade social serem congeladas entre 2012 e 2014; a Espanha retirou a compensação do índice de preços ao consumidor; e, no Chipre, aboliu-se o transporte gratuito e o bônus de Páscoa para os aposentados ${ }^{27}$.

Diante disso, não foi sem razão que, em muitos países membros da União Europeia, milhares de pessoas saíram às ruas em protesto às políticas de austeridade adotadas, que manifestamente reduziram a qualidade de vida e sobrevivência de muitos cidadãos europeus (SENADO FEDERAL, 2013). A população, em especial a de baixa renda, não apenas se viu tolhida de relevantes serviços públicos de educação e saúde, como também tiveram que assumir parte do ônus da política de cortes adotada por seus Estados, com aumento da tributação e cortes significativos na previdência - cerceamento de direitos que implica em quadro alarmante.

O estudo realizado para a Comissão de Liberdades Civis, Justiça e Assuntos Internos do Parlamento Europeu (2015) conclui que as políticas de austeridade, aplicadas desde o início da crise econômica, afetaram os sistemas que garantem os direitos fundamentais, o que gera uma crescente preocupação, pois as medidas austeras podem não cumprir com o objetivo principal de recuperação econômica, bem como cercear e inviabilizar direitos inegociáveis, no âmbito do Estado Democrático de Direito.

\footnotetext{
${ }^{25}$ Ob. cit., p. 87.

${ }^{26}$ Ob. cit., p. 87.

${ }^{27}$ EUROPEAN PARLIAMENT, 2015, p. 87.
} 


\section{O CENÁRIO DE CRISE ECONÔMICA NO BRASIL E A ADOÇÃO DE MEDIDAS DE AUSTERIDADE: AMEAÇAS AOS DIREITOS SOCIAIS PELAS POLÍTICAS DE CORTES}

Uma vez analisados os impactos concretos das medidas de austeridade no acesso aos direitos à educação, à saúde e à previdência, conforme apurado no estudo de sete países membros da União Europeia, realizado para a Comissão de Liberdades Civis, Justiça e Assuntos Internos do Parlamento Europeu (2015), a tendência no Brasil de adoção dessas medidas de cortes para controle dos gastos públicos desperta preocupações.

A crise econômica no Brasil, atribuída a uma série de fatores, teve seu início por volta de 2014, para muitos analistas, instaurando um período de séria recessão no país. O perfil tradicional de fornecedor de matérias-primas e produtos primários, bem como as desigualdades estruturais diante do crescimento econômico - consequência direta do sistema capitalista, em que nem todos os segmentos da sociedade são beneficiados - contribuíram para o agravamento da situação socioeconômica no Brasil, com a crise econômica de 2008 (EXAME, 2019).

Embora o governo iniciado em 2003 tenha proporcionado um país estabilizado e com inflação controlada, foi adotada uma política fiscal austera, aliada a uma política monetária rígida e restritiva, juntamente a uma meta de superávit primário, “cumprida com folga de $41,7 \%$ a meta para o primeiro semestre de $2004 " 28$. Como plano de crescimento econômico, o governo aplicou uma política de juros subsidiados e crédito barato para os empresários por ele escolhidos, além de se tornar um grande investidor, realizando inúmeras obras públicas.

Consequentemente, a renda das classes mais baixas foi elevada, promovendo mudanças nos hábitos de consumo e investimentos, e, claro, aumento das demandas por parte da população brasileira - o que culminou em programas e incentivos na educação, saúde, saneamento e assistência básica, estendendo-se nos anos seguintes.

Com o advento da crise econômica mundial que se instalou a partir de 2008, o governo brasileiro aplicou medidas que garantissem que o mercado interno, agora maior, continuasse a sustentar a demanda brasileira. Desse modo, a população assistiu a isenções de impostos em

${ }^{28}$ BANCO CENTRAL DO BRASIL, 2004, p. 3.

Revista de Direitos Sociais, Seguridade e Previdência Social | e-ISSN: 2525-9865 | Belém | v. 5 | n. 2 | p. 23 - 44 | Jul/Dez. 2019. 
produtos industrializados (eletrodomésticos, automóveis) e incentivos fiscais no setor da construção civil.

No entanto, evidente que tais medidas estimularam o consumo, "sem o devido investimento em produtividade, infraestrutura e educação" (FECOMERCIO-SP, 2016), acarretando o endividamento do cidadão brasileiro e encarecimento dos serviços públicos, e, assim, o desequilíbrio econômico, segundo o economista Ricardo Amorim ${ }^{29}$.

Em 2010, após novas eleições presidenciais, o governo manteve as políticas de juros subsidiados, crédito de baixo custo aos empresários aliados, bem como taxas de exoneração, isenção fiscal e desvalorização cambial. Houve, ainda, o congelamento de tarifas públicas para evitar o aumento da inflação (FECOMERCIO-SP, 2016).

Com a perpetuação dessas medidas de "aquecimento econômico", o país entrou em recessão técnica em meados de 2014, havendo queda da produção industrial, dos salários reais e do "PIB em 3,8\% em 2015", de acordo com o divulgado pelo Instituto Brasileiro de Geografia e Estatística (IBGE, 2019) ${ }^{30}$.

$\mathrm{Na}$ tentativa de driblar o desequilíbrio macroeconômico, o governo, em 2015, anunciou aumentos de impostos sobre as transações financeiras, tais como, o Imposto sobre Produtos Industrializados (IPI) e o Imposto sobre Operações Financeiras (IOF) ${ }^{31}$.

Assim, com a crise econômica, acompanhada da impopularidade do governo de Dilma Rousseff, então presidente do Brasil, que não foi capaz de articular alianças entre seu partido e aliados (culminando em seu processo de impeachment), a queda do Produto Interno Bruto (PIB) brasileiro em 2016 já era esperada por muitos economistas. Porém, o que causou preocupante surpresa foi o fato de que o baque foi muito maior que o esperado.

Consoante dados divulgados pelo IBGE (2019), entre 2014 e 2016, o PIB brasileiro registrou "queda de 2,4\%",32, atingindo a agropecuária, a indústria e a oferta de serviços. Escândalos de corrupção à parte, com a desconfiança dos investidores no mercado brasileiro, acrescida da falta de reforma política eficiente que venha a promover cortes de gastos e reformulações legislativas nas áreas realmente necessárias, bem como a queda no consumo pelo aumento do desemprego, instaurou-se no Brasil um período de recessão que, para muitos, está longe do seu fim.

\footnotetext{
${ }^{29}$ FECOMERCIO-SP, 2016.

${ }^{30}$ IBGE. Evolução da taxa de crescimento do PIB brasileiro, $1^{\circ}$ trimestre de 1996 a $2^{\circ}$ trimestre de 2019.

${ }^{31}$ FECOMERCIO-SP, 2016.

${ }^{32}$ IBGE, 2019.
} 
Neste contexto, como dantes visto nos Estados Unidos e nos países europeus, o atual governo brasileiro tem optado por adotar postura mais austera, a fim de implementar políticas de ajuste e contenção de despesas públicas, realizando cortes orçamentários em áreas que entende necessárias, buscando o equilíbrio econômico, partindo da mesma mentalidade de que o país não cresce porque gasta demais.

Ocorre que, assim como observado no estudo para a Comissão de Liberdades Civis, Justiça e Assuntos Internos do Parlamento Europeu (2015), as políticas de austeridade podem afetar severamente direitos fundamentais, notadamente os direitos socias à educação, à saúde e à previdência.

Os cortes de verbas públicas no Ministério da Educação e Cultura, promovidos pelo atual governo, atingem a educação como um todo. Além do corte de "30\% nos investimentos das universidades federais do país" ${ }^{\text {33 }}$, sob o argumento de favorecer a educação básica, o valor do congelamento nos investimentos da educação "ultrapassa R 7 bilhões"34, e na educação básica “o valor já é de R\$ 914 milhões” (MARIZ, 2019). O corte, ainda, inclui verbas para construção e manutenção de escolas e creches, capacitação de profissionais da educação, merendas escolares e transporte.

Não obstante o dever do governo de observar as normas estabelecidas na Lei Complementar Federal n ${ }^{\text {o }} 101$, de 04 de maio de 2000, a "Lei de Responsabilidade Fiscal", e o teto de gastos da Emenda Constitucional no 95, de 15 de dezembro de 2016 - por meio da qual foi instituído o Novo Regime Fiscal no âmbito dos Orçamentos Fiscal e da Seguridade Social da União -, os cortes na educação prejudicam demasiadamente a qualidade do ensino público, vez que serão desencadeadas reduções no número de escolas e de servidores públicos do setor, além do comprometimento dos serviços públicos complementares: transporte escolar, alimentação de crianças de baixa renda em idade escolar, e falta de prédios em condições adequadas e seguras para profissionais e estudantes - algo já experimentado por países membros da União Europeia.

Na saúde, a vigência da austeridade expressa na Emenda Constitucional nº 95/2016 e o aprofundamento das políticas do atual governo, estão causando a degradação do Sistema Único de Saúde (SUS). De acordo com estudo liderado pelo Departamento de Saúde Global e

\footnotetext{
${ }^{33}$ MARIZ, 2019.

${ }^{34}$ Ob. cit., 2019.
} 
População da Harvard T. H. A Chang School of Public Health (DIAS, 2019), as principais conquistas obtidas nos últimos trinta anos com o SUS estão se deteriorando rapidamente.

Os pesquisadores apontam que, em análise de "quatro cenários em cerca de trinta indicadores entre demográficos, epidemiológicos, econômicos e dos sistemas de saúde״ ${ }^{, 35}$, em todos os casos "os índices pioraram, sobretudo para os municípios menores e mais pobres, com menor capacidade de arrecadação e maior dependência de verbas da União" (CASTRO et. al., 2019, p. 6).

Veja-se que as restrições fiscais implementadas com a Emenda Constitucional $\mathrm{n}^{\circ}$ 95/2016 inauguraram um período de retrocesso nas conquistas obtidas pelo Sistema Único de Saúde.

\begin{abstract}
A defesa da saúde como um direito, combinada à criatividade e à capacidade de superar as adversidades, fez do SUS um exemplo de inovação do sistema de saúde para a América Latina e uma referência ao mundo. Esse legado não pode (e não deve) ser desperdiçado. No futuro, à medida que o novo contexto se desenrola, $\mathrm{o}$ efeito de novas políticas sobre os resultados em saúde, as disparidades e o bem-estar da sociedade como um todo deve ser analisado criticamente para avaliar as consequências das políticas fiscais, econômicas, ambientais, educacionais e de saúde na população brasileira ${ }^{36}$. (CASTRO et. al., 2019, p. 10).
\end{abstract}

Tendo em vista as novas diretrizes ambientais, educacionais e de saúde do atual governo, há a possibilidade de reversão dos progressos obtidos pelo Brasil, comprometendo a sustentabilidade do SUS e a capacidade de cumprimento do dever constitucional do Estado em prestar os cuidados de saúde aos cidadãos.

A partir da experiência de países europeus que vivenciam as consequências de cortes na saúde em decorrência da crise econômica, não se pode permitir que a universalidade das políticas de saúde seja prejudicada pela falta de financiamento adequado e de recursos devidamente alocados.

Por fim, no tocante à previdência, as críticas às medidas adotadas são ainda maiores. $\mathrm{O}$ atual governo defende a necessidade de aprovação da Reforma da Previdência, sustentando que o cenário de turbulência econômica também é decorrente do sistema previdenciário vigente que contribui para o colapso das contas públicas.

${ }^{35}$ CASTRO et. al., 2019, p. 6

36 "The defence of health as a right, combined with creativity and the ability to overcome adversity, made the SUS an example of health system innovation for Latin America and a reference to the world. That legacy cannot (and should not) be squandered. Looking ahead, as the new context unfolds, the effect of new policies on health outcomes, disparities and the wellbeing of the society as a whole must be critically examined to assess the consequences of fiscal, economic, environmental, education, and health policies on the Brazilian population" (tradução livre) 
Entretanto, da forma em que se encontra, o projeto de Reforma da Previdência em processo de aprovação no Congresso Nacional mantém o caráter austero das políticas de governo, vindo a prejudicar os mais pobres e necessitados do país, retirando de circulação da economia "R\$ 1 trilhão em dez anos, como anunciou o Ministro da Economia, Paulo Guedes" (INSTITUTO TRICONTINENTAL DE PESQUISA SOCIAL, 2019).

Dessa forma, ao promover as políticas de cortes, o atual governo estará reduzindo a renda dos trabalhadores e pensionistas, já que o reajuste do sistema previdenciário nas aposentadorias e pensões não acompanhará o índice do salário mínimo e o novo cálculo do benefício terá o seu valor reduzido. Logo, aqui também, haverá o risco de ameaçar seriamente direitos sociais fundamentais dos cidadãos, sem conseguir resgatar o país da crise econômica - preocupação já compartilhada pelos governos de Estados membros da União Europeia.

Às portas do caos econômico, o momento não poderia ser para cortes drásticos e aumento da inflação. Pois, com a inflação em alta, tem-se a redução da renda dos assalariados, sem ganho real e retração da economia. Ou seja, ao invés de melhora, tem-se o agravamento do quadro de crise.

Atividade econômica desaquecendo, investimentos recuando e uma taxa de desemprego que não cede; esses dados comprovam que fazer ajuste com a economia em desaceleração não gera um novo ciclo de desenvolvimento, pelo contrário, com os recursos já subempregados, os cortes no gasto público geram redução da demanda e desemprego. (INSTITUTO TRICONTINENTAL DE PESQUISA SOCIAL, 2019)

Seja nos cortes na educação e na saúde, seja na reforma do sistema de previdência, é possível identificar denominadores comuns que influenciam nas violações dos direitos mais fundamentais das pessoas, vez que as políticas de austeridade favorecem o aumento das desigualdades sociais, a degradação das relações laborativas com a redefinição da jornada de trabalho e das condições de precariedade do trabalho, e o retrocesso nas políticas de educação e de saúde.

Entrementes, no contexto em que muitos países, que no passado adotaram medidas severas de austeridade, estão reconsiderando tal postura, preocupando-se com os impactos nos direitos dos cidadãos, parece ser um retrocesso a ascensão do discurso da austeridade econômica no Brasil.

Com o advento da Emenda Constitucional n 95/2016, houve a constitucionalização da austeridade, e, se não for revista o quanto antes pelos Poderes Executivo e Legislativo, o 
desmonte das políticas públicas e, consequentemente, a ameaça aos direitos, precipuamente sociais, irão subsistir.

Diante de uma economia em crise, a adoção de políticas de cortes pode desencadear um "círculo vicioso de austeridade": com as medidas de cortes, há redução dos investimentos públicos e, logo, redução das demandas do setor privado; com isso, queda do crescimento do PIB e da arrecadação físcal do Estado, deteriorando o resultado primário, levando a novas reduções de despesas (DWECK et. al., 2018, p.18).

No estudo sobre os resultados das políticas de austeridade no Brasil, transformado no livro "Economia para poucos - impactos sociais da austeridade e alternativas para o Brasil" (DWECK et. al., 2018), apurou-se que as medidas de cortes tiveram efeitos semelhantes aos observados em diversos países da periferia europeia, consoante identificado no relatório da Comissão de Liberdades Civis, Justiça e Assuntos Internos do Parlamento Europeu (EUROPEAN PARLIAMENT, 2015).

Diferentemente do prometido, as políticas de austeridade não trouxeram o tão almejado equilíbrio econômico. Ao contrário: os cortes acabaram agravando a recessão e a frustração de receitas do governo. E pior: as medidas podem proporcionar prejuízo aos direitos sociais, com evidente redução do acesso à educação, aos cuidados de saúde e à previdência.

\section{CONCLUSÃO}

De fato, encontrar o ponto de equilíbrio entre a redução de gastos públicos e o estímulo ao crescimento não é tarefa fácil. Principalmente, em momentos de caos econômico.

No entanto, os direitos fundamentais dos indivíduos, resultado de conquistas históricas ao longo do tempo, não podem ser atropelados, como se fossem facilmente inefetivados face a argumentos econômico-financeiros. Direitos como acesso à educação, à saúde e à previdência, reconhecidamente inalienáveis no âmbito do Estado Democrático de Direito, não podem ser submetidos ao crivo da discricionariedade dos governos de países em crise econômica.

A inevitabilidade das políticas de austeridade não é regra. É possível às economias desenvolvidas lidarem com a turbulência financeira, sem implementar cortes tão drásticos, elaborando medidas que não venham a cercear os direitos sociais - principais alvos da 
contenção e ajuste das despesas públicas.

Por meio do estudo realizado para a Comissão de Liberdades Civis, Justiça e Assuntos Internos do Parlamento Europeu (2015), constata-se a experiência alarmante de sete países membros da União Europeia, cujas as consequências a direitos fundamentais como educação, saúde e previdência foram danosas, ao ponto de reduzir a qualidade de vida dos cidadãos europeus, sobretudo os mais pobres, que se viram sem escolas, sem assistência médica e sem dinheiro.

Em um contexto de crise econômica, a austeridade é contraproducente, pois tende a provocar queda da atividade econômica e aumento da dívida pública, resultando no oposto ao que a política de cortes propõe. E, a redução de investimentos públicos em áreas sociais (como educação, saúde e previdência), a fim de enrijecer a política econômica para controle dos gastos públicos, não contribui para recolocar o país na rota do crescimento.

Tendo em vista os resultados apurados em sete países membros da União Europeia, pelo estudo "O impacto da crise nos direitos fundamentais em Estados-Membros da UE análise comparativa" (EUROPEAN PARLIAMENT, 2015), e os efeitos já percebidos das medidas de austeridade adotadas pelo atual governo brasileiro, nas áreas de educação, saúde e previdência, há um sério risco de a economia brasileira se retrair e ser deflagrado novo período de recessão, acompanhado de grave cerceamento de direitos sociais.

Sabe-se que a austeridade tem profundos impactos sociais, que acabam por atingir de forma desproporcional e essencialmente a população mais vulnerável: pobres, idosos, mulheres, portadores de deficiência, crianças em idade escolar, negros e imigrantes.

Faz-se necessário romper o discurso de que não há alternativas, que o único caminho são os cortes. Em tempos de crise econômica, o objetivo é tornar os governos mais disciplinados com relação às suas finanças e convencer os mercados de que os países não têm a possibilidade de descontrole de seus gastos.

Evidente que os atuais governos, não apenas no Brasil como no mundo, iniciados no cenário pós-crise, terão dificuldades de se distanciarem das políticas de austeridade. No Brasil, enquanto a Emenda Constitucional n ${ }^{\circ}$ 95/2016 permanecer sem alterações, o governo terá de apertar o cinto - o que implica no decote constante e progressivo das políticas públicas.

Não se pode olvidar que a garantia dos direitos fundamentais estabelece relação intrínseca com o orçamento público. A austeridade não pode ser a única opção. Promover 
cortes nas despesas públicas, pura e simplesmente, sem se pensar nos impactos gerados aos cidadãos em seus direitos, é banalizar o que foi conquistado a duras penas, e esvaziar a função primordial do Estado: garantir a proteção e o acesso aos direitos por todos.

\section{REFERÊNCIAS}

BANCO CENTRAL DO BRASIL. Perspectivas para a Relação Dívida Pública/PIB. Focus, 5 ago. 2004. Disponível em: https://www4.bcb.gov.br/gci/Focus/F20040805Perspectivas\%20da\%20D\%C3\%ADvida\%20P\%C3\%BAblica.pdf. Acesso em 30 ago. 2019.

BLYTH, Mark. Austeridade: a história de uma ideia perigosa. Trad. Freitas e Silva (ebook). São Paulo: Autonomia Literária, 2017.

BRASIL. Constituição (1988). Constituição da República Federativa do Brasil. 48. ed. São Paulo: Saraiva, 2013.

BAUMAN, Zygmunt. Globalização: As consequências humanas. Trad. Marcus Penchel (ebook). Rio de Janeiro: Zahar, 1999.

CASTRO, Marcia C. Castro; MASSUDA, Adriano; ALMEIDA, Gisele; MENEZES-FILHO, Naercio Aquino; ANDRADE, Monica Viegas; NORONHA, Kenya Valéria Micaela de Souza; ROCHA, Rudi; MACINKO, James; HONE, Thomas; TASCA, Renato; GIOVANELLA, Ligia; MALIK, Ana Maria; WERNECK, Heitor; FACHINI, Luiz Augusto; ATUN, Rifat. Brazil's unified health system: the first 30 years and prospects for the future.

The Lancet. Health Policy, 11 jul. 2019. Disponível em: https://www.abrasco.org.br/site/wpcontent/uploads/2019/07/PIIS0140673619312437.pdf. Acesso em 21 ago. 2019.

DIAS, Bruno C. Estudo aponta degradação do SUS frente à austeridade e governo Bolsonaro. Abrasco - Notícias, 12 jul. 2019. Disponível em:

https://www.abrasco.org.br/site/outras-noticias/sistemas-de-saude/estudo-aponta-degradacaode-30-anos-de-conquistas-do-sus-frente-a-austeridade-e-governo-bolsonaro/41683/. Acesso em 3 ago. 2019.

DWECK, Esther; OLIVEIRA, Ana Luíza Matos de; ROSSI, Pedro (Coord.). Austeridade e retrocesso: impactos sociais da política fiscal no Brasil. $1^{\text {a }}$ ed. São Paulo: Brasil Debate e Fundação Friedrich Ebert, 2018.

(Org.). Economia para

poucos - Impactos sociais da austeridade e alternativas para o Brasil. São Paulo:

Autonomia Literária, 2018.

EUROPEAN PARLIAMENT. The impact of the crisis on fundamental rights across Member States of the EU - Comparative analysis (Study). Directorate General for Internal Policies. Policy Department C: Citizens' Rights and Constitutional Affairs. Civil Liberties, Justice and Home Affairs: Brussels, 2015. Disponível em: 
http://statewatch.org/news/2015/mar/ep-study-cris-fr.pdf. Acesso em 5 ago. 2019.

EXAME. PIB do Brasil só recuperou $30 \%$ do que foi perdido na crise econômica - IBGE divulgou PIB do segundo trimestre, que subiu $0,4 \%$; durante a recessão dos anos de 2015 e 2016, o PIB acumulou uma retração de 8,2\%. São Paulo: Economia, 29 ago. 2019. Disponível em: https://exame.abril.com.br/economia/pib-do-brasil-so-recuperou-30-do-quefoi-perdido-na-crise-economica/. Acesso em 30 ago. 2019.

FECOMERCIO-SP. FEDERAÇÃO DO COMÉRCIO DE BENS, SERVIÇOS E TURISMO DO ESTADO DE SÃO PAULO. PIB do Brasil só recuperou $30 \%$ do que foi perdido na crise econômica - IBGE divulgou PIB do segundo trimestre, que subiu $0,4 \%$; durante a recessão dos anos de 2015 e 2016, o PIB acumulou uma retração de 8,2\%. Economia, 16 mar. 2016. Disponível em: https://www.fecomercio.com.br/noticia/crise-e-reflexo-dedesequilibrios-macroeconomicos-gerados-pelo-governo-diz-o-economista-ricardo-amorim. Acesso em 30 ago. 2019.

GONÇALVES, Reinaldo. Globalização Econômica. O nó econômico. Capítulo 1. Instituto de Economia, Universidade Federal do Rio de Janeiro (UFRJ). Rio de Janeiro: Record, 2002. Disponível em: http://www.ie.ufrj.br/intranet/ie/userintranet/hpp/arquivos/texto_no._1_globalizacao_economi ca.pdf. Acesso em 5 ago. 2019.

IBGE. INSTITUTO BRASILEIRO DE GEOGRAFIA E ESTATÍSTICA. Evolução da taxa de crescimento do PIB brasileiro. PIB a preços de mercado - Taxa acumulada em 4 trimestres (\%), $1^{\circ}$ trimestre $1996-2^{\circ}$ trimestre 2019. Disponível em: https://www.ibge.gov.br/estatisticas/economicas/contas-nacionais/9300-contas-nacionaistrimestrais.html?edicao=20920\&t=series-historicas. Acesso em 30 ago. 2019.

INSTITUTO TRICONTINENTAL DE PESQUISA SOCIAL. Economicamente inviável: cortes de Bolsonaro e Guedes não geram crescimento. Brasil de Fato - Uma visão popular do Brasil e do mundo - Colunistas, 24 jul. 2019. Disponível em:

https://www.brasildefato.com.br/2019/07/24/economicamente-inviavel-cortes-de-bolsonaro-eguedes-nao-geram-crescimento/. Acesso em 5 ago. 2019.

MARIZ, Renata. Cortes no MEC afetam educação básica, anunciada como prioridade por Bolsonaro Área perdeu pelo menos R\$ 914 milhões; ao todo, Ministério da Educação terá bloqueados R\$ 7,4 bilhões. Brasília: Jornal O Globo - Sociedade, 6 mai. 2019. Disponível em: https://oglobo.globo.com/sociedade/cortes-no-mec-afetam-educacaobasica-anunciada-como-prioridade-por-bolsonaro-23646433. Acesso em 12 jul. 2019.

MENDES, Gilmar Ferreira; COELHO, Inocêncio Mártires; BRANCO, Paulo Gustavo Gonet. Curso de direito constitucional. São Paulo: Saraiva, 2007.

PEREIRA, Anna Carolina Migueis. Crise econômica e direitos sociais: uma análise sobre a constitucionalidade de restrições a direitos prestacionais. Revista Estudos Institucionais. Rio de Janeiro, v. 3, n. 2, 2017. Disponível em:

https://estudosinstitucionais.com/REI/article/view/209/174. Acesso em 5 ago. 2019. 
REIS, Tiago. Crise do Subprime: Entenda o que foi e como afetou a economia mundial. Suno Research - Economia. [S.I] 24 jul. 2018. Disponível em:

https://www.sunoresearch.com.br/artigos/crise-do-subprime/. Acesso em 5 ago. 2019.

SAMPAIO, José Adércio Leite. Teoria da constituição e dos direitos fundamentais. Belo Horizonte: Del Rey, 2013.

SARMENTO, Claudia. Cenário econômico na Europa há dez anos e nos dias de hoje. Londres: Jornal O Globo - Economia, 9 set. 2018. Disponível em:

https://oglobo.globo.com/economia/cenario-economico-na-europa-ha-dez-anos-nos-dias-dehoje-23037977. Acesso em 12 jul. 2019.

SENADO FEDERAL. Causas da crise na Europa (o problema fiscal e a enorme dívida pública) e as consequências (piora na relação dívida pública / PIB, reservas baixas e o aumento das taxas de desemprego). Em Discussão - Revista de audiências públicas do Senado Federal. Brasília, ano 4, n. 16 jul. 2013. Disponível em:

https://www.senado.gov.br/noticias/Jornal/emdiscussao/contas-publicas/mundo/causas-dacrise-na-europa-o-problema-fiscal-enorme-divida-publica-consequencias-reservas-baixas-oaumento-das-taxas-de-desemprego-divida-publica-em-relacao-ao-pib.aspx. Acesso em 12 jul. 2019. 